\title{
A!
}

This is an electronic reprint of the original article.

This reprint may differ from the original in pagination and typographic detail.

Henn, Alexander; Mattinen, Maija-Liisa

\section{Valued Applications of Lignin Nanoparticles}

\section{Published in:}

Recent Progress in Materials

DOI:

10.21926/rpm.1902001

Published: $26 / 04 / 2019$

Document Version

Publisher's PDF, also known as Version of record

Published under the following license:

CC BY

Please cite the original version:

Henn, A., \& Mattinen, M-L. (2019). Valued Applications of Lignin Nanoparticles. Recent Progress in Materials , 1(2), 1-9. https://doi.org/10.21926/rpm.1902001

This material is protected by copyright and other intellectual property rights, and duplication or sale of all or part of any of the repository collections is not permitted, except that material may be duplicated by you for your research use or educational purposes in electronic or print form. You must obtain permission for any other use. Electronic or print copies may not be offered, whether for sale or otherwise to anyone who is not an authorised user. 
Opinion

\title{
Valued Applications of Lignin Nanoparticles
}

\author{
Alexander Henn ${ }^{+, *}$, Maija-Liisa Mattinen ${ }^{\dagger, *}$
}

Bioproduct Chemistry, Department of Bioproducts and Biosystems, School of Chemical

Engineering, Aalto University, P.O. Box 16300, FI-00076 Aalto, Espoo, Finland; E-Mails:

karl.henn@aalto.fi; maija-liisa.mattinen@aalto.fi

+ These authors contributed equally to this work.

* Correspondence: Alexander Henn; Maija-Liisa Mattinen; E-Mails: karl.henn@aalto.fi; maija.mattinen@outlook.com

Academic Editor: Hossein Hosseinkhani

Special Issue: $\underline{\text { Applications and Development of Biomaterials in Medicine }}$

Recent Progress in Materials

2019, volume 1 , issue 2

doi:10.21926/rpm.1902001
Received: March 08,2019

Accepted: April 19, 2019

Published: April 26, 2019

\begin{abstract}
Technical lignins from the biorefinery, pulp, and paper industries are largely underutilized, even though this aromatic and randomly structured biopolymer could be an interesting raw material for advanced applications in addition to bulk daily goods. Recently, colloidal lignin particles (CLPs) have gained much of the research interests due to the attractive multifunctional properties of the biopolymer. Utilization of lignin in nanoparticulate morphology resolves most of the drawbacks when using lignin (heterogeneity and low solubility). Stable lignin nanodispersions in different formulations is an attractive method to prepare tailored nanobiomaterials. Potential value-added applications include adhesives for wound sealing, edible coatings for foods, fiber modification for textiles to improve adhesion, hydrophobicity, antimicrobial and anti-oxidative properties of the material, as recently shown using chamois and nanocellulose model matrixes. Moreover, CLPs could be used as carriers for enzymes, emulsifiers for colloids, adsorbents in water purification and controlled-release vectors for drugs and pesticides. In this contribution the recent advances are highlighted.
\end{abstract}

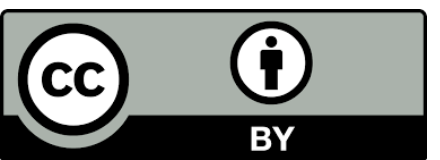

(C) 2019 by the author. This is an open access article distributed under the conditions of the Creative Commons by Attribution License, which permits unrestricted use, distribution, and reproduction in any medium or format, provided the original work is correctly cited. 


\section{Keywords}

Lignin; nanoparticle; coating; functionalization; medicine; foods; cosmetics

\section{Preparation of Colloidal Lignin Particles}

Green technologies for the preparation of nanobiomaterials from the forest process sidestreams as lignin are increasing rapidly [1-21]. Tailored colloidal lignin particles could be produced in the laboratory at a semi-industrial scale [22-29]. The most prominent method for the preparation of smooth spherical lignin nanoparticles (NPs) is solvent switching using tetrahydrofuran or acetone and water, in other words, solvents with a large difference in polarity [14-16]. Irregularly shaped particles can be formed by sonicating lignin suspensions [3, 10, 15]. However, fundamentals of the CLP formation are far from understood due to the random structure of the biopolymer. It has been proposed that the process may start from the formation of tiny particles $(<100 \mathrm{~nm}$ ) colliding with each other, growing to large aggregates. Then, the most phenolic and hydroxyl-rich parts of the polymeric lignin adsorbs onto the surface of the aggregates forming negatively charged surfaces [30]. Stability of the CLPs towards alkali and organic solvents can be enhanced using chemical and enzymatic cross-linking [18, 19, 31, 32].

\section{Functionalization of the Particles}

Silkworm adhesive containing NPs is an interesting biomimetic model for the adhering of different surfaces [33]. Strong agglutination at the interface is a result of the large surface area of the NPs forming a viscous matrix between the layers. There, they act as connectors dissipating energy under stress [34]. The nanosize of the particles ensures tight adhesion. Non-cytotoxic CLPs $[3,35,36]$ on the surfaces could function accordingly and their function can even be improved and modified via coating or chemical surface functionalization of the particles to meet requirements of a broad range of applications [37-40]. Qian et al. [6] showed that atom radial transfer polymerization (ATRP) could be used to graft 2-(diethylamino)ethyl methacrylate groups to lignin following NP formation via $\mathrm{CO}_{2}$-bubbling. Kai et al. [11] used ring opening polymerization (ROP) to graft poly lactic acid (PLA) to lignin to prepare fibrous nanocomposites. Yang et al. [12] linked caprolactone-co-lactide to lignin to form a rubbery phase following poly $\varepsilon$-caprolactone (PCL) grafting and lignin-g-PCL NP formation via ROP. Including small reactive molecules in the hydrophobic core of the CLPs, specificity of the particles could be further tailored [41]. These examples show that CLP are easy to customize in different steps of the NP formation and methods for functionalization are vast. Combining different approaches such as coating, infusion, polymerization, enzymatic and chemical cross-linking the possibilities for the modifications are nearly unlimited. 


\section{Applications}

\subsection{Medical}

Adhesives based on above nanobridging mechanism via inorganic NPs [42] and colloidal mesoporous silica (CMS) particles [43] have been proposed as alternatives for traditional medical adhesives [34] comparable to CLPs used to stabilize pickering emulsions [44]. Nanocellulose fibrils (CNF) and bacterial nanocellulose $(\mathrm{BC})$ are lightweight and transparent polymers, making them excellent raw materials for tissue regeneration [45-48]. The major challenge for the exploitation of CNF is the poor stability of the fibrils in physiological conditions. Capability to obtain tight bonding between tissue edges to prevent bleeding and to get strong sealing are crucial properties for medical adhesives [42, 49,50]. These adhesives are often toxic and unstable at physiological $\mathrm{pH}$ requiring complex in vivo analytical systems for curing reactions [51]. Feasibility to coat CNF with different CLPs using thermal cross-linking was demonstrated recently [19]. The method could be an effective way to improve mechanical strength and stability of CNF. Especially tiny CLPs prepared from enzymatically polymerized lignin [18] with specific protein coating could be potential additives for such applications [19]. Additionally, the colloidal structure of NPs enables faster decomposition of the particles in biological media than inorganic NPs, hindering undesirable accumulation in the body. The strong autofluorescence of lignin enable sensitive real time detection of the CLPs using microscopy, crucial for the development of image-guided procedures for clinical applications [51]. Enzymatic and thermal curing are fast and feasible in a moist environment [19]. CLP formation via solvent switching is an attractive method to infuse NPs with antibacterial agents as silver ions [3,4]. CLPs could be also co-precipitated with oil-soluble drugs as Resveratrol commonly used for cancer treatments [35]. In the cell, the drug is either slowly released via diffusion, or the structure of CLP is degraded [3, 30, 35]. CLPs magnetized by precipitating NPs with a magnetic salt or a magnetic mineral such as $\mathrm{Fe}_{3} \mathrm{O}_{4}$ enable efficient control of the particles in living systems with NMR imaging [36, 51].

\subsection{Food and Cosmetics}

Food and medical applications are closely related. Food packages based on petroleum-based raw materials are not biodegradable. They have poor oxygen barrier properties possibly leaching harmful compounds into the foods. Water soluble edible coatings based on dairy proteins could be excellent alternatives for such packages $[52,53]$. Nanospheres prepared from caseins form thin films and have been used to coat foods and other biological tissues [54, 55]. However, the poor water resistance and mechanical strength of these coatings could be improved using CLPs coated with $\beta$-casein [19]. Furthermore, using CLPs as functional ingredient in polylactic acid (PLA) blends, wheat gluten composites and polyvinyl alcohol (PVOH) and chitosan films, mechanical properties of the materials was shown to be improved [8, 9, 12, 13]. Enhanced UV-protection and antibacterial property of the blends made them interesting additives for food packaging and cosmetic products, as sunscreens $[7,56]$. The UV-shielding property of lignin in sunscreens has been studied using both CLPs and polymeric lignin as an additive. The modified sunscreens had broad protection factors and could be prepared simply by adding CLPs into commercial cosmetic products. Large colloidal spheres were better UV-blockers than polymeric lignin. Furthermore, CLPs had a synergetic effect with UV-blocking substances present in the commercial sunscreens, 
significantly enhancing their performance. Moreover, modified CLPs could be effective emulsifying agents for $\mathrm{O} / \mathrm{W}$ pickering emulsions for foods and cosmetic products $[10,40]$.

\subsection{Textiles}

In addition to adherence, CNF and chamois CLPs have been used to agglutinate protein matrix via $\beta$-casein coating following enzymatic cross-linking for fast curing [19]. In that way, it was possible to obtain stronger elastic agglutinations between the soft surfaces. Clearly, the type of biopolymer affected the strength, flexibility, and elongation of the joint significantly. Enzymatic cross-linking reactions have been used to strengthen polymeric lignin-containing technical glues as well [57]. Studies with soybean-based adhesives containing lignin showed that the protein - lignin ratio is the most critical parameter affecting the adhesive interactions [58, 59]. Apparently, exploitation of technical lignin in nanoparticle morphology for adhering soft material following enzymatic curing is a potential approach for fibre modification to be used in textiles as shown with silk and protein particles [60].

\subsection{Bio and Chemical Industry}

As discussed above, ionic substances can be infused into CLPs [4], rendering them potentially useful for wastewater treatment. Due to different ionizable groups, CLPs have strong buffering effect towards neutral $\mathrm{pH}$ increasing the applicability of CLPs for wastewater refinement. This application could be accomplished in several ways. Wei et al. [44] showed that CLPs could be used to stabilize $\mathrm{O} / \mathrm{W}$ emulsions for water purification processes to remove hazardous oil-soluble substances like styrene. CLP-coated styrene particles could be de-emulsified to recover the lignin and remove the styrene form the water phase. It has been also shown that emulsified lignin particles could be used as nanosized chambers for silver nucleation reactions [12]. When O/Wemulsified lignin particles, containing silver nitrate and sodium borohydrate separately, were mixed in an aqueous solution, metallic silver particles were formed [61]. Qian et al. [6] prepared controllable $\mathrm{O} / \mathrm{W}$ emulsions containing decane by grafting 2-(diethylamino)ethyl methacrylate to lignin following $\mathrm{CO}_{2}$-bubbling for NP formation. De-emulsification occurred when the dispersion was bubbled with nitrogen gas, yielding a gas-switchable emulsion expanding the use of CLPs for a broad range of applications when controllability is required. It has also been shown that enzymes such as lipases and cutinases could be anchored to cationic CLPS, enabling them to catalyze esterification reactions in water solutions [17]. Then intermediately sized esters, like butyl butyrate, could be separated from the water phase, enabling simple and efficient processes for product purification and renewing of the whole process.

\section{Conclusions}

In this contribution, a range of recent applications for technical lignin in nanoparticle morphology is summarized. Clearly, the valorisation of lignin to water-dispersible nanoparticles resolves many of the bottlenecks that isolated lignin has faced during the past decades, making it an excellent raw material for many value-added applications, such as wound-healing, controlled drug release, and green antibacterial agents for medical and cosmetic products. CLPs could also be used in daily items like packaging and textiles, but also for more technical purposes like 
nanoreactors, anchors for biocatalysts, additives for composites [62], and adhesives [63,64]. Increasing lignin research focusing on the NP preparation and functionalization including scale-up of the methods might lead to a promising future for the world's second most abundant biopolymer. In the pursuit of a greener future, technical lignin will undoubtedly play a great role in the economy globally.

\section{Author Contributions}

Henn A planned and wrote the preliminary version of the manuscript as well as performed the literature review. Mattinen $M-L$ supervised the work as well as wrote and edited the final version of the manuscript.

\section{Funding}

Not applicable.

\section{Competing Interests}

The authors have declared that no competing interests exist.

\section{References}

1. Babu RP, O'Connor K, Seeram R. Current progress on bio-based polymers and their future trends. Prog Biomater. 2013; 2: 8.

2. Norgren M, Edlund H. Lignin: Recent advances and emerging applications. Curr Opin Colloid Interface Sci. 2014; 19: 409-416.

3. Nypelö TE, Carrillo CA, Rojas OJ. Lignin supracolloids synthesized from (W/O) microemulsions: Use in the interfacial stabilization of Pickering systems and organic carriers for silver metal. Soft Matter. 2015; 11: 2046-2054.

4. Richter AP, Brown JS, Bharti B, Wang A, Gangwal S, Houck K, et al. An environmentally benign antimicrobial nanoparticle based on a silver-infused lignin core. Nat Nanotechnol. 2015; 10: 817-823.

5. Liu X, Yin H, Zhang Z, Diao B, Li J. Functionalization of lignin through ATRP grafting of poly (2dimethylaminoethyl methacrylate) for gene delivery. Colloids Surfaces B Biointerfaces. 2015; 125: 230-237.

6. Qian Y, Zhang Q, Qiu X, Zhu S. CO2-responsive diethylaminoethyl-modified lignin nanoparticles and their application as surfactants for CO2/N2-switchable Pickering emulsions. Green Chem. 2014; 16: 4963-4968.

7. Qian Y, Qiu X, Zhu S. Lignin: A nature-inspired sun blocker for broadspectrum Sunscreens. Green Chem. 2015; 17: 320-324.

8. Sun Y, Yang L, Lu X, He C. Biodegradable and renewable poly(lactide)-lignin composites: Synthesis, interface and toughening mechanism. J Mater Chem A. 2015; 3: 3699-3709.

9. Yang W, Owczarek JS, Fortunati E, Kozanecki M, Mazzaglia A, Balestra GM, et al. Antioxidant and antibacterial lignin nanoparticles in polyvinyl alcohol/chitosan films for active packaging. Ind Crops Prod. 2016; 94: 800-811. 
10. Tortora M, Cavalieri F, Mosesso P, Ciaffardini F, Melone F, Crestini C. Ultrasound driven assembly of lignin into microcapsules for storage and delivery of hydrophobic molecules. Biomacromolecules. 2014; 15: 1634-1643.

11. Kai D, Ren W, Tian L, Chee PL, Liu Y, Ramakrishna S, et al. Engineering poly(lactide)-lignin nanofibers with antioxidant activity for biomedical application. ACS Sustain Chem Eng. 2016; 4: 5268-5276.

12. Yang W, Fortunati E, Dominici F, Kenny JM, Puglia D. Effect of processing conditions and lignin content on thermal, mechanical and degradative behavior of lignin nanoparticles/polylactic (acid) bionanocomposites prepared by melt extrusion and solvent casting. Eur Polym J. 2015; 71: 126-139.

13. Yang W, Kenny JM, Puglia D. Structure and properties of biodegradable wheat gluten bionanocomposites containing lignin nanoparticles. Ind Crops Prod. 2015; 74: 348-356.

14. Qian Y, Deng Y, Qiu X, Li H, Yang D. Formation of uniform colloidal spheres from lignin, a renewable resource recovered from pulping spent liquor. Green Chem. 2014; 16: 2156-2163.

15. Frangville $C$, Rutkevičius M, Richter AP, Velev OD, Stoyanov SD, Paunov VN. Fabrication of environmentally biodegradable lignin nanoparticles. ChemPhysChem. 2012; 13: 4235-4243.

16. Lievonen M, Valle-Delgado JJ, Mattinen ML, Hult EL, Lintinen K, Kostiainen MA, et al. A simple process for lignin nanoparticle preparation. Green Chem. 2016; 18: 1416-1423.

17. Sipponen MH, Farooq M, Koivisto J, Pellis A, Seitsonen J, Österberg M. Spatially confined lignin nanospheres for biocatalytic ester synthesis in aqueous media. Nat Commun. 2018; 9: 2300.

18. Mattinen ML, Valle-Delgado JJ, Leskinen T, Anttila T, Riviere G, Sipponen M, et al. Enzymatically and chemically oxidized lignin nanoparticles for biomaterial applications. Enzyme Microb Technol. 2018; 111: 48-56.

19. Mattinen M-L, Riviere G, Henn A, Nugroho R, Leskinen T, Nivala O, et al. Colloidal lignin particles as adhesives for soft materials. Nanomaterials. 2018; 8: 1001.

20. Didaskalou C, Buyuktiryaki S, Kecili R, Fonte CP, Szekely G. Valorisation of agricultural waste with an adsorption/nanofiltration hybrid process: From materials to sustainable process design. Green Chem. 2017; 19: 3116-3125.

21. Li Y, Zhou M, Pang Y, Qiu X. Lignin-based microsphere: Preparation and performance on encapsulating the pesticide avermectin. ACS Sustain Chem Eng. 2017; 5: 3321-3328.

22. Ashok B, Oinas P, Lintinen K, Sarwar G, Kostiainen MA, Österberg M. Techno-economic assessment for the large-scale production of colloidal lignin particles. Green Chem. 2018; 20: 4911-4919.

23. Ago M, Huan S, Borghei M, Raula J, Kauppinen El, Rojas OJ. High-throughput synthesis of lignin particles ( $\sim 30 \mathrm{~nm}$ to $\sim 2 \mu \mathrm{m}$ ) via aerosol flow reactor: Size fractionation and utilization in pickering emulsions. ACS Appl Mater Interfaces. 2016; 8: 23302-23310.

24. Beisl S, Miltner A, Friedl A. Lignin from micro- to nanosize: Production methods. Int J Mol Sci. 2017; 18: 1244.

25. Gilca IA, Popa VI, Crestini C. Obtaining lignin nanoparticles by sonication. Ultrason Sonochem. 2015; 23: 369-375.

26. Nair SS, Sharma S, Pu Y, Sun Q, Pan S, Zhu JY, et al. High shear homogenization of lignin to nanolignin and thermal stability of nanolignin-polyvinyl alcohol blends. ChemSusChem. 2014; 7: 3513-3520. 
27. Richter AP, Bharti B, Armstrong HB, Brown JS, Plemmons D, Paunov VN, et al. Synthesis and characterization of biodegradable lignin nanoparticles with tunable surface properties. Langmuir. 2016; 32: 6468-6477.

28. Lintinen K, Xiao Y, Bangalore Ashok R, Leskinen T, Sakarinen E, Sipponen M, et al. Closed cycle production of concentrated and dry redispersible colloidal lignin particles with a three solvent polarity exchange method. Green Chem. 2018; 20: 843-850.

29. Leskinen $T$, Smyth $M$, Xiao $Y$, Lintinen $K$, Mattinen $M-L$, Kostiainen $M A$, et al. Scaling up production of colloidal lignin particles. Nord Pulp Pap Res J. 2019; 32: 586-596.

30. Sipponen $\mathrm{MH}$, Lange $\mathrm{H}$, Ago $\mathrm{M}$, Crestini $\mathrm{C}$. Understanding lignin aggregation processes. A case study: Budesonide entrapment and stimuli controlled release from lignin nanoparticles. ACS Sustain Chem Eng. 2018; 6: 9342-9351.

31. Roth S, Spiess AC. Laccases for biorefinery applications: A critical review on challenges and perspectives. Bioprocess Biosyst Eng. 2015; 38: 2285-2313.

32. Munk L, Sitarz AK, Kalyani DC, Mikkelsen JD, Meyer AS. Can laccases catalyze bond cleavage in lignin? Biotechnol Adv. 2015; 33: 13-24.

33. Stewart RJ, Wang CS, Shao H. Complex coacervates as a foundation for synthetic underwater adhesives. Adv Colloid Interface Sci. 2011; 167: 85-93.

34. Rose $S$, Prevoteau A, Elzière $P$, Hourdet $D$, Marcellan A, Leibler L. Nanoparticle solutions as adhesives for gels and biological tissues. Nature. 2014; 505: 382-385.

35. Dai L, Liu R, Hu LQ, Zou ZF, Si CL. Lignin nanoparticle as a novel green carrier for the efficient delivery of resveratrol. ACS Sustain Chem Eng. 2017; 5: 8241-8249.

36. Figueiredo $P$, Lintinen $K$, Kiriazis A, Hynninen V, Liu Z, Bauleth-Ramos $T$, et al. In vitro evaluation of biodegradable lignin-based nanoparticles for drug delivery and enhanced antiproliferation effect in cancer cells. Biomaterials. 2017; 121: 97-108.

37. Mohammadinejad R, Karimi S, Iravani S, Varma RS. Plant-derived nanostructures: Types and applications. Green Chem. 2015; 18: 20-52.

38. Leskinen T, Witos J, Valle-Delgado JJ, Lintinen K, Kostiainen M, Wiedmer SK, et al. Adsorption of proteins on colloidal lignin particles for advanced biomaterials. Biomacromolecules. 2017; 18: 2767-2776.

39. Forsman N, Lozhechnikova A, Khakalo A, Johansson LS, Vartiainen J, Österberg M. Layer-bylayer assembled hydrophobic coatings for cellulose nanofibril films and textiles, made of polylysine and natural wax particles. Carbohydr Polym. 2017; 173: 392-402.

40. Sipponen $\mathrm{MH}$, Smyth $\mathrm{M}$, Leskinen $\mathrm{T}$, Johansson LS, Österberg M. All-lignin approach to prepare cationic colloidal lignin particles: Stabilization of durable Pickering emulsions. Green Chem. 2017; 19: 5831-5840.

41. Sipponen $M H$, Lange $H$, Crestini $C$, Henn A, Österberg M. Lignin for nano-and microscaled carrier systems: Applications, trends and challenges. ChemSusChem. 2019. DOI: 10.1002/cssc.201900480.

42. Meddahi-Pellé A, Legrand A, Marcellan A, Louedec L, Letourneur D, Leibler L. Organ repair, hemostasis, and in vivo bonding of medical devices by aqueous solutions of nanoparticles. Angew Chem Int Ed Engl. 2014; 53: 6369-6373.

43. Kim JH, Kim H, Choi Y, Lee DS, Kim J, Yi GR. Colloidal mesoporous silica nanoparticles as strong adhesives for hydrogels and biological tissues. ACS Appl Mater Interfaces. 2017; 9: 3146931477. 
44. Wei Z, Yang $Y$, Yang R, Wang C. Alkaline lignin extracted from furfural residues for $\mathrm{pH}$ responsive Pickering emulsions and their recyclable polymerization. Green Chem. 2012; 14: 3230.

45. Bhattacharya M, Malinen MM, Lauren $P$, Lou YR, Kuisma SW, Kanninen L, et al. Nanofibrillar cellulose hydrogel promotes three-dimensional liver cell culture. J Control Release. 2012; 164: 291-298.

46. Lou YR, Kanninen L, Kuisma T, Niklander J, Noon LA, Burks D, et al. The use of nanofibrillar cellulose hydrogel as a flexible three-dimensional model to culture human pluripotent stem cells. Stem Cells Dev. 2014; 23: 380-392.

47. Petersen N, Gatenholm P. Bacterial cellulose-based materials and medical devices: Current state and perspectives. Appl Microbiol Biotechnol. 2011; 91: 1277-1286.

48. Lin N, Dufresne A. Nanocellulose in biomedicine: Current status and future prospect. Eur Polym J. 2014; 59: 302.

49. de Oliveira $\mathrm{CL}$, dos Santos CHM, Bezerra FMM, Bezerra MM, de Lima Rodrigues L. Utilização de adesivos de cianoacrilatos em suturas de pele. Rev Bras Cir Plást (Impr). 2011; 25: 573-576.

50. Peng HT, Shek PN. Novel wound sealants: Biomaterials and applications. Expert Rev Med Devices. 2010; 7: 639-659.

51. Shin K, Choi JW, Ko G, Baik S, Kim D, Park OK, et al. Multifunctional nanoparticles as a tissue adhesive and an injectable marker for image-guided procedures. Nat Commun. 2017; 8: 15807.

52. Bonnaillie L, Aburto L, Tunick M, Mulherin J, Du M, Kwoczak R, et al. Advances in food packaging films from milk proteins. American Chemical Society National Meeting. 2016.

53. Bonnaillie LM, Tomasula PM. Application of humidity-controlled dynamic mechanical analysis (DMA-RH) to moisture-sensitive edible casein films for use in food packaging. Polymers (Basel). 2015; 7: 91.

54. Zhang F, Ma J, Xu Q, Zhou J, Simion D, Carmen G, et al. Hollow Casein-Based Polymeric Nanospheres for Opaque Coatings. ACS Appl Mater Interfaces. 2016; 8: 11739-11748.

55. Pan K, Zhong Q. Organic nanoparticles in foods: Fabrication, characterization, and utilization. Annu Rev Food Sci Technol. 2016; 7: 245-266.

56. Qian Y, Zhong X, Li Y, Qiu X. Fabrication of uniform lignin colloidal spheres for developing natural broad-spectrum sunscreens with high sun protection factor. Ind Crops Prod. 2017; 101: 54.

57. Aracri E, Díaz Blanco C, Tzanov T. An enzymatic approach to develop a lignin-based adhesive for wool floor coverings. Green Chem. 2014; 16: 2597-2603.

58. Luo J, Luo J, Yuan C, Zhang W, Li J, Gao Q, et al. An eco-friendly wood adhesive from soy protein and lignin: Performance properties. RSC Adv. 2015; 5: 100849-100855.

59. Pradyawong S, Qi G, Li N, Sun XS, Wang D. Adhesion properties of soy protein adhesives enhanced by biomass lignin. Int J Adhes Adhes. 2017; 75: 66-73.

60. Cortez J, Anghieri A, Bonner PLR, Griffin M, Freddi G. Transglutaminase mediated grafting of silk proteins onto wool fabrics leading to improved physical and mechanical properties. Enzyme Microb Technol. 2007; 40: 1698-1704.

61. Hu S, Hsie Y-L. Silver nanoparticle synthesis using lignin as reducing and capping agents: A kinetic and mechanistic study. Int J Biol Macromol. 2016; 82: 856-862. 
62. Tian D, Hu J, Bao J, Chandra RP, Saddler JN, Lu C. Lignin valorization: Lignin nanoparticles as high-value bio-additive for multifunctional nanocomposites. Biotechnol Biofuels. 2017; 10: 192.

63. Lima García J, Pans G, Phanopoulos C. Use of lignin in polyurethane-based structural wood adhesives. J Adhes. 2018; 94: 814-828.

64. Kalami S, Arefmanesh M, Master E, Nejad M. Replacing $100 \%$ of phenol in phenolic adhesive formulations with lignin. J Appl Polym Sci. 2017; 134: 45124-45133.

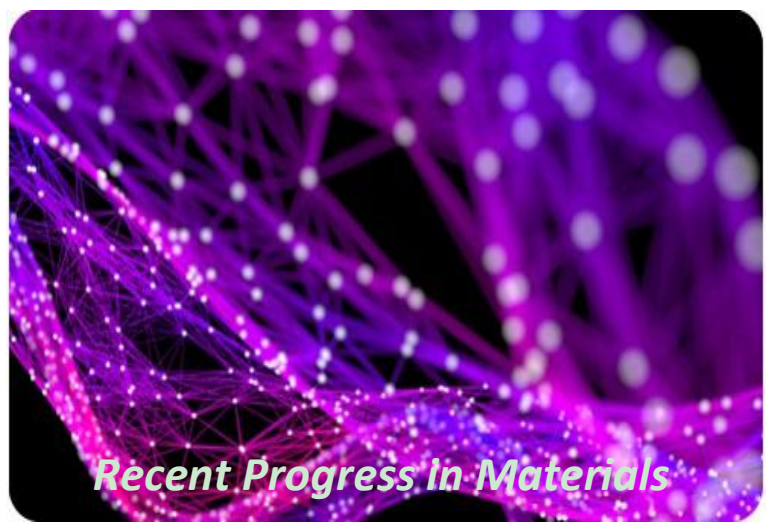

Enjoy Recent Progress in Materials by:

1. Submitting a manuscript

2. Joining in volunteer reviewer bank

3. Joining Editorial Board

4. Guest editing a special issue

For more details, please visit:

http://www.lidsen.com/journals/rpm 